\title{
Resilience, Optimism and Social Support among International Students
}

\author{
Fatemeh Sabouripour ${ }^{1} \&$ Samsilah Bte Roslan ${ }^{1}$ \\ ${ }^{1}$ Department of Educational Studies, University Putra Malaysia, Serdang, Malaysia \\ Correspondence: Samsilah Bte Roslan, Putra Science Park, University Putra Malaysia, Serdang, 43400, Malaysia. \\ Tel: 60-38-947-1291. E-mail: samsilah@upm.edu.my
}

\author{
Received: January 4, 2015 Accepted: February 5, 2015 Online Published: May 15, 2015 \\ doi:10.5539/ass.v11n15p159 URL: http://dx.doi.org/10.5539/ass.v11n15p159
}

\begin{abstract}
This study focuses on the examination of the relationship between resilience, optimism and social support among international students. International students who are studying as foreign students tend to experience greater stress and anxiety during their study. They need to adjust to the new environment and overcome challenges. The resilience level of students is very important as it can help them adjust their life pressures and stresses. The current study aims to look at the levels and patterns of resilience, optimism and social support among international students. The instruments used were Connor-Davidson Resilience Scale (CD-RISC) for resilience, Life Orientation Test Revised (LOT-R) for optimism and Multidimensional Scale of Perceived Social Support (MSPSS) for social support. A total of 291 international students were involved in the study. The findings revealed a significant difference in the resiliency level across races, with African students scoring higher than others. The regression analysis employed showed that optimism $(B=.593)$ and social support $(B=.204)$ are significant predictors of resilience.
\end{abstract}

Keywords: resilience, optimism, social support, race, gender, international students

\section{Introduction}

Naturally, a person's mental system might be able to decrease the effects of migration on mental and physical health. Recent studies not only show that it is difficult to eliminate all college stressors, but they also focus on examining how students cope with the challenges (Pritchard, Wilson, \& Yamnitz, 2007). It has been suggested that how well an individual copes with a transition is related to how much an individual is resilient (Tusaie \& Dyer, 2004). According to Friborg, Hjemdal, Rosenvinge, and Martinussen (2003) resilience has a great significance on adjusting adequately to life stressors. Psychological resilience is defined as the individual's capability in coping with stress and adversity, which may see the individual returning to an earlier state of normalcy with no indications of negative effects (Masten, 2009). Resilience can be better explained as the opportunity and capacity of individuals to find psychological, social, cultural, and physical resources that will provide for their well-being, and their prospect and ability alone or with others, to benefit from these resources and in culturally meaningful ways (Ungar, 2008). There is a direct relationship between resilience and levels of stress; in other words, higher resilience scores predict lower levels of stress (Hjemdal, Vogel, Solem, Hagen, \& Stiles, 2011).

In line with this, Walker et al. (2006) showed some conceptual differences in resilience pertaining to university students in their higher education. They point to the association of resilience and the determination to carry on even when confronted by adversity. Resilience is proven to play a significant role in coping with stressors and therefore in improving performance. While there is an abundance of research in the literature with a focus on the relationship among influencing factors on college adjustment, there is relatively less research on the relationship among such factors on students' own resilience. Previous literature stated that students who are resilient are able to manage the challenges that they face during transition to a university in a foreign country and they are academically successful (Compas, Wagner, Slavin, \& Vannatta, 1986; Gall, Evans, \& Bellerose, 2000). Resilient students deal with some difficulties such as loneliness and separation, language, immigration status, discrimination, and financial concerns (Reynoso, 2008). In the context of Asia, Chan (2000) revealed that Asian students with high level of resilience, get significantly less impact from negative events compared to students with low level of resilience. They are also more motivated and have higher self-confidence both academically and socially (Chan, 2000). In addition, a study in Malaysia by Lee (2011) revealed that people who have low levels of resilience will fail to cope with stressful situations. The implication is that highly resilient youths will 
fare better in facing challenges than those with low resilience. It is also indicated that those with resilience are better able to employ active social coping strategies (Li, 2008; Yi-Frazier et al., 2010).

Furthermore, it has been empirically proven that there are variations in resilience from one student to another, thus suggesting that it is a variable depending on the influence of several factors. This means that the variations in resilience must be the result of some internal and external factors that are protective and related to the level of resilience in people (Troy \& Mauss, 2011). Review of previous study revealed that optimism (a mental tendency that construes situation as being best) and social support (existence of some people, including friends and family who care and support in times of need) are two dominant factors influencing the level of resilience (Bonanno, 2004; Dawson \& Pooley, 2013; Rutter, 2006; Soenens et al., 2007; Tugade \& Fredrickson, 2007).

In addition, past studies have suggested the influence of race and gender on resilience (Harris, 2004). Clauss-Ehlers, Yang, and Chen (2006) revealed that robust race identities predicted resilience in responding to stress, pointing to the possible significance of cultural resilience in coping for some ethnic communities.

Studies that examine the relationship between optimism, social support and resilience are lacking in Malaysia, although there are studies that examine these variables separately (Lee, 2011; Tam \& Lim, 2009). Accordingly, gaps to be investigated in this research relate to the lack of quantitative description of resilience as a product of other variables. Furthermore, there is a need to understand the concept of resilience and the possible predictors among international students, particularly in Malaysia. What is important is for this research to seek empirical evidence of the roles of optimism and social support in predicting resilience as they are skills which can be enhanced, taught and learned (Carver \& Connor-Smith, 2010; Fresco, Moore, Walt, \& Craighead, 2009; Meevissen, Peters, \& Alberts, 2011).

The specific research objectives of the study are as follows:

1) To explore the level and patterns of resilience across race among international students.

2) To explore the level and patterns of resilience across gender among international students.

3) To investigate the relationship between optimism and resilience.

4) To investigate the relationship between social support and resilience.

In order to achieve the objectives of the study a research framework was established.

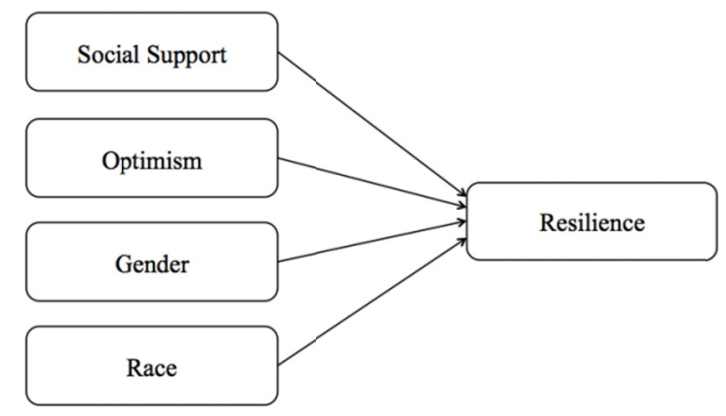

Figure 1. The relationship between social support, optimism, gender and race with resilience

\subsection{Literature Review}

\subsubsection{Resilience}

Resilience is the capability to bounce back from misfortune. In other word, resilience refers to an ability to cope with challenging issues. Uri Bronfenbrenner developed ecological system theory and he believed that there is a need to understand persons' development into their environment. An ecological model of factors affecting resiliency demonstrates that resiliency is a function of a network of bi-directional effects which embraces the organic factors ( gender, temperament, intelligence) and individual's internal world of thoughts and feelings (problem-solving and analysis skills, optimism and autonom), his or her family, school and the immediate neighborhood, and eventually the wider world, where factors such as national mental health strategies, the global economic climate, culture, and the media come into play (Bronfenbrenner, 1986). Originally, resilience was conceptualized as a personality trait; however, in recent years, it has been more often taught as a series of protective factors, which a person can draw upon in difficult times. An antecedent to resiliency, moreover, is previous experience of adversity, while the most notable result of resiliency is having good coping skills to 
manage repeated adversity in life (Earvolino-Ramirez, 2007). The concept of resilience has been inspected in various fields of psychology, including developmental psychology, trauma recovery, formative psychology and the study of competence under stress. In the view of Tugade and Fredrickson (2007), resilience implies the ability to effectively cope with and adapt to adversity. Zautra, Hall, and Murray (2010) posit that the best definition of resilience is that it is the ability to adapt successfully to difficult and hostile situations, at the same time they point to the significance of personal characteristics which play a major role in determining how successful a human will be in adapting to the adverse circumstance.

\subsubsection{Optimism and Resilience}

In this study optimism is defined as an inherent tendency to expect favorable future results and it is related to making positive evaluations of the circumstances, and taking the time to actively engage coping strategies in dealing with stress (Carver \& Scheier, 2003). Also, it is an attitude of hope that good things can occur in one's life and it seems to be a personal difference variable that represents the degree of people's generalized positive expectations for their future (Carver \& Connor-Smith, 2010). General life optimism is connected to positive moods, achievement, popularity, perseverance, effective problem solving, good health and confidence (Beard, Hoy, \& Woolfolk Hoy, 2010). Also, being optimistic can have an influential and positive impact on the individual's capability to adapt to stressors. From a resilience point of view, optimism has been found to be linked to psychological well-being when confronted with adversity, better physical health, and adaptive coping mechanism (Carver \& Connor-Smith, 2010).

Past literature has indicated the importance of being optimistic in enhancing resilience; optimism has also been proven to be the most crucial factor, cognitively, among adolescents, in their capability to cope with stress (Tusaie-Mumford, 2001). Generally, it appears that resilience is a reflection of the intention to be optimistic in the face of challenges Rutter (2006); this means that in situations of stress optimism complements resilience (Carver \& Connor-Smith, 2010). Additionally, it has been proposed that being optimistic will help individuals cope with the move to university (Soenens et al., 2007). Also, optimism is positively associated with: academic achievement, well-being, effortful control (self-regulation), academic performance, social and academic adjustment, autonomous motivation (self-determination), persistence and choice of coping strategies (Lekes, Gingras, Philippe, Koestner, \& Fang, 2010; Ratelle, Larose, Guay, \& Senécal, 2005; Soenens et al., 2007). Tusaie and Patterson (2006) studied three different forms of optimism partly to try and understand the concepts that help to maximize resilience. Their findings indicated that optimism was a crucial cognitive factor in the moderation and reduction of stress. This is primarily because trait optimism is defined as a constant and generalized expectation that there will be positive outcomes (Scheier, Carver, \& Bridges, 1994). A study on urban minorities with limited opportunities revealed that optimism characterized resilience among a group of high school students pursuing a college preparation career academy (Conchas \& Clark, 2002). In general, it appears that conceptually, resilience involves a desire to be optimistic when facing adversity (Rutter, 2006). This implies that resilience is accompanied by optimism in the face of stress and therefore optimism plays an important role in an individual's capability to adapt to stress (Carver, Scheier, \& Segerstrom, 2010). When confronted with a challenge, those who are optimistic are still able to show resilience, even though progress may be slow and difficult (Snyder, Feldman, Shorey, \& Rand, 2002). Hence, it is proposed that:

H1: There is a relationship between resilience and optimism among international students.

\subsubsection{Social Support and Resilience}

Social support is defined by Hale, Hannum, and Espelage (2005) in several areas, encompassing emotional support, informational assistance, intimacy, comfort and physical kindness. Hale et al. (2005) defined perceived social support as having somebody to suggest help, when such assistance is needed. Social support can come from the emotional history of family, friends and one's equals. It can also be forthcoming as a result of interacting with one's social circle, including with professionals and even with the environment (Greenberger, Chen, Tally, \& Dong, 2000). In fact, social support is a meta-concept which encompasses different dimensions of perceived and functionally realized social exchange, such as satisfaction with the quality and quantity of support, feeling cared for, respected and being connected in one's social network (Chronister, Johnson, \& Berven, 2006). Smaller social networks, fewer close relationships, and lower perceived adequacy of social support have been linked to psychological distress and especially depressive symptoms and psychological health (Kawachi \& Berkman, 2001). In order to remain physically and mentally healthy, students must have strong social support, which generally can strengthen resilience to encounter stress (Faith, Douglas \& Eleni, 2007). Burcusa and Iacono (2007) argued that social support not only protects individuals against depression, but also has been placed within related resilience. 
Social support is positively associated with promoting psychological well-being, intrinsic motivation, social and school bonding, school adjustment, self-esteem, choice of coping strategies, self-reliance, academic achievement and contributes to resilience (Bernardon, Babb, Hakim-Larson, \& Gragg, 2011). Wilks and Spivey (2010) revealed that social support systems have a quite considerable positive impact on resilience. The findings of the study indicate that friend-related social support minimized the negative association between academic stress and resilience. The interaction between friend support and academic stress impacted positively on resilience among students (Wilks \& Spivey, 2010).

Social support has been proposed as a resource to effectively manage stress and cope successfully among social work students via its relationship to construct from several empirical measures, such as measures on stress, anxiety, and self-efficacy (Dziegielewski, Turnage, \& Roest-Marti, 2004; Greenberger et al., 2000). Typically, social support comes from two main areas, family and friends, and work colleagues or supervisors (Taylor \& Friedman, 2007). As such, a supportive relationship with a teacher, other family members, and peers had a direct relation to increased levels of educational resilience. These conclusions have been proven to be true of various studied groups. Dent and Cameron (2003) discovered that youth with resilience exhibited a sense of belonging and connectedness of individuals, groups, and institutions more frequently than their counterparts who were non-resilient. Such resilient youths also showed stronger feelings of independence and personal involvement when talking about their lives, and were perfectly clear and positive about what they planned to do in the future, compared to the youths who were non-resilient. Then, it is assumed that:

$\mathrm{H} 2$ : There is a relationship between resilience and social support among international students.

\subsubsection{Resilience, Gender and Race}

With reference to demographic variables, Clauss-Ehlers, Yang, and Chen (2006) found that race and gender identities have significantly linked with level of resilience in difficult situations. Also, this research investigated how stress and resilience were related between a various groups of women in college. Furthermore, gender may have a crucial impact on how pessimistic or optimistic coping strategies and resilience develops (Dweck \& Reppucci, 1973). Fergusson, Horwood, and Swain-Campbell (2003) stated that females showed greater resilience to externalizing responses (alcohol dependence, antisocial personality disorder, and participation in criminal activities), while males showed greater resilience to internalizing responses (depression, anxiety, suicidal tendencies, and ideation).

It can be seen that various studies on gender-based resilience continue to show mixed results. For example, DuMont, Widom, and Czaja (2007) have concluded that females show greater resilience while other studies found greater resilience in males (Tusaie, Puskar, \& Sereika, 2007). Moreover, a study by Weidong et al. (2012) among 600 college students indicated that resilience had significant differences between male and female students. Also, some researchers have investigated gender differences in risk and resilience factors, and they revealed females are more resilient than males and also females are less exposed to risky behaviors than males (Wright \& Masten, 2005).

Besides, an investigation of psychosocial resilience among adolescents showed males to be more resilient than females (Tusaie et al., 2007). DuMont et al. (2007) investigated the factors that predicted resilience in children who had experienced abuse and neglect and the findings revealed that female adolescents in early adulthood showed greater resilience. And also DuMont et al. (2007) investigated abused and neglected African American adolescents and found that they exhibited greater resilience than their white counterparts. Wilson, Hurtt, Shaw, Dishion, and Gardner (2009) in an eight-year longitudinal study of African Americans, Whites, and Hispanics in three United States regions discovered African Americans show greater resilience compared to their White and Hispanic colleagues, considering that they were exposed to risks such as frequent mobility, low-income, hazardous neighborhoods, substance abuse by parents, single mother homes, etc. In summary, it would be concluded:

H3. There is a difference in the resilience level across race among international students.

H4: There is a difference in the resilience level across gender among international students.

\section{Method}

\subsection{Participant}

The sample consisted of 291 international students of University Putra Malaysia. The participants were selected using multistage sampling. In the first stage, cluster random sampling is used whereby one faculty is randomly selected from the 5 clusters in UPM. The next stage is proportionate stratified random sampling in which students are randomly sampled from each faculty according to the ratio of the total students in the five faculties. 
As stated in Table 1, 51.9\% of respondents were male and $48.1 \%$ were female. Majority of the students were single $(68.4 \%)$ and the rest married (31.6\%). Middle-Easterners make up $40.5 \%$ of the sample, Asians and Africans constitute $24.1 \%$ and $35.4 \%$ respectively. More than half of the respondents $(66 \%)$ were in the age group of 26-29, $21 \%$ in the age group of 22-25 and the rest of them (13\%) were in the age group of 30 and older. Large numbers of students (48.5\%) were supported by their families, $26.8 \%$ spent their personal saving, $18.6 \%$ of them received a scholarship, and $3.4 \%$ worked full-time, the $2.7 \%$ of respondents worked part-time.

Table 1. Sample profile

\begin{tabular}{ccc}
\hline Variables $(\mathrm{n}=291)$ & Frequency & Percentage (\%) \\
\hline Gender & 151 & 51.9 \\
Male & 140 & 48.1 \\
Female & & \\
Marital status & 199 & 68.4 \\
Single & 92 & 31.6 \\
Married & 188 & 40.5 \\
Race & 70 & 24.1 \\
Middle- east & 103 & 35.4 \\
Asian & & \\
African & 61 & 21.0 \\
Age & 192 & 66.0 \\
$22-25$ & 38 & 13.0 \\
$26-29$ & 8 & 2.7 \\
30< & 10 & 3.4 \\
Finance & 141 & 48.5 \\
Work part- time & 54 & 18.6 \\
Work full- time & 78 & 26.8 \\
Family & & \\
Scholarship & & \\
Personal saving & &
\end{tabular}

\subsection{Research Instrument}

Demographic variables: Participants in this study first completed a short demographic form that collected their gender, age, race and marital status. Previous studies showed the relation of these variables with resilience. However, the focus of this study was on international students; so, race and gender were used as a demographic variable.

Resilience: Connor-Davidson Resilience Scale (CD-RISC) was utilized to assess resilience scale. The CD-RISC is a 25-item scale which aims to determine the ability to deal effectively with stress and adversity. Examples of items are: "I am able to adapt when changes occur," "I tend to bounce back after illness, injury, or other hardships," and "I am able to handle unpleasant or painful feelings like sadness, fear, and anger". The CD-RISC in the present study demonstrated a reliable measurement (Cronbach alpha 0.924) in assessing resilience.

Optimism: Optimism was assessed by using the Life Orientation Test Revised (LOT-R) of Scheier and Carver 1985 , this scale is a 7-item assessment of individual differences of optimism, which is comprised of optimistic statements ("In uncertain times, I usually expect the best", "I'm always optimistic about my future"," Overall, I expect more good things to happen to me than bad") (Shorey et al., 2007). The study demonstrated clear factor structure and good internal consistency reliability coefficient 0.921 .

Social support: Multidimensional Scale of Perceived Social Support (MSPSS) was adopted to measure social support level (Zimet, Dahlem, Zimet, \& Farley, 1988). The MSPSS is a 12-item scale by which perceived social support from three various sources, namely family, friends, and a significant other will be assessed. Sample items consist of "There is a special person with whom I can share my joys and sorrows" "My family really tries to help me" and "I can talk about my problems with my friends." Current study obviously showed an internal consistency reliability coefficient 0.818 .

\subsection{Research Design and Data Analysis}

The study conducted a correlation design to make comparisons between variables. Descriptive statistics used in this study were frequencies, percentages, means, and standard deviations. Furthermore, linear regression was 
employed to ascertain the intensity and direction of the relationship among the variables of resilience, optimism and social support. Also, one-way ANOVA was used to compare the mean differences of races and resilience. Moreover, independent t-test was conducted to determine differences in resilience level across gender. All analysis was performed with SPSS 20. Also, for all variables 5-point Likert-type scale was used $(1=$ strongly disagree to $5=$ strongly agree).

As preliminary analyses descriptive statistics, reliability estimates (Cronbach's alpha coefficients), and bivariate zero-order correlations in all the study variables are presented in Table 2 . The cumulative mean of the items was 3.82 with a standard deviation of 0.49 . The overall mean of optimism factors was 3.7 with a standard deviation of 0.61 . The overall mean of the social support was 3.81 with a standard deviation of 0.74 .

Pearson correlation was utilized to investigate the relationship between optimism, social support and resilience among international students. As stated in Table 2, the result illustrates a significant positive and strong relationship between optimism, social support and resilience $(r=.706, p<.01, r=.523, p<.01)$. In regards to checking assumption of normality, linearity, outliers, multicolinearity and homogeneity of variance preliminary testing has been performed to ensure no serious violation. Skewness and Kurtisus less than \pm 2 indicated normal distribution of data (Lomax \& Schumacker, 2012). According to table 2, skewenes and kurtisus are less than \pm 2 . Moreover, multicolinearity assumption is a threat when there is a high inter correlation between variables $>$. 9 or colinearity statistics show $1<$ Tolerance and $10<$ VIF (Creswell, 2009). As stated by correlation test result and colinearity statistics test, there was no violation regarding multicolinearity and linearity assumptions and overall study meets the assumptions.

Table 2. Descriptive statistics, reliability and Pearson Correlation between research variables

\begin{tabular}{|c|c|c|c|c|c|c|c|c|}
\hline Item & Variable & Mean & SD & Skewenes & Kurtisus & 1 & 2 & 3 \\
\hline 1 & Resilience & 3.82 & 0.49 & -0.66 & 1.11 & 0.92 & & \\
\hline 2 & Optimism & 3.7 & 0.61 & -.0 .68 & 0.25 & $.71 * * *$ & 0.92 & \\
\hline 3 & Social support & 3.81 & 0.74 & -0.63 & 0.34 & $.53 * * *$ & $.55 * * *$ & 0.82 \\
\hline
\end{tabular}

Hair et al., 2010), Skewness and kurtisus $<2$.

\section{Results}

An independent sample t-test was employed to compare the resilience score for male and female. Based on results in Table 3, there was no significant difference in the level of resilience across gender among the students. According to the result of independent t-test, the mean value of the male is mean=96. 88 with $\mathrm{SD}=12.44$ and mean value for female students were mean $=94.52$ with $\mathrm{SD}=12.31$. The differences in the means were about 2.36 with small effect size (eta squared $=.004$ ).

Table 3. Results of independent sample t-test for examining the difference between resilience and gender

\begin{tabular}{lccccccc}
\hline Gender & N & M & SD & Mean difference & Df & T & P \\
\hline Male & 151 & 96.88 & 12.44 & 2.36 & 289 & 1.625 & P $>0.05$ \\
Female & 140 & 94.52 & 12.31 & & & & \\
\hline
\end{tabular}

According to Table 4, the one-way ANOVA was conducted to explore the differences between three race groups (group 1: Middle-east, group 2: Asian, group 3: African) and level of resilience. The results alluded that there was a statistically significant difference between races with $\mathrm{F}(2,288)=6.55$ and $\mathrm{p}<.05$ regarding the level of resilience. The actual difference in mean scores between groups was quite large. The effect size, calculated using eta squared, was 0.43 .

Table 4. Result of one-way ANOVA: comparison of differences between resilience and race

\begin{tabular}{lcccc}
\hline Race & Mean & S.D. & F & P \\
\hline Middle-east & 92.66 & 12.1 & 6.55 & .002 \\
Asian & 97.1 & 9.25 & & \\
African & 98.34 & 13.99 & & \\
Total & 95.74 & 12.42 & & \\
\hline
\end{tabular}

Note. Sig. at 0.01 levels 
According to Table 5, the Welch test was conducted to identify the significant differences between pair groups. Tamhane Post Hoc test revealed a significant difference between Middle-Easterners with Asian and African. It should be concluded that Middle-Easterners gain the lowest level of resilience compared to Asian and African students. And, the African gain highest level of resilience to compare other groups.

Table 5. Tamhane Post Hoc test of resilience and race multiple comparisons

\begin{tabular}{llccc}
\hline Race & & Mean Difference & Std. Error & Sig. \\
\hline Middle-east & Asian & -4.43 & 1.56 & $.015^{*}$ \\
& African & -5.67 & 1.76 & $.005^{* *}$ \\
Asian & African & -1.23 & 1.76 & .863 \\
African & Middle-east & 4.43 & 1.56 & $.015^{*}$ \\
& Asian & 1.23 & 1.76 & .863 \\
& Middle-east & 5.67 & 1.76 & $.005^{*}$ \\
\hline
\end{tabular}

Note. Sig. at the *0.05,**0. 01 level

According to table 6 , $\mathrm{R}$ square value indicated that two- predictor explained about $52.8 \%$ of the variance in resilience. Based on the ANOVA table, the model fit data with $\mathrm{f}=160.98$ and $\mathrm{p}<.001$. It is concluded that there was linear regression coefficient between resilience and the two predictors. Additionally, the standardized beta value revealed that there was a high contribution of optimism with $\mathrm{B}=.593$ and social support with $\mathrm{B}=.204$ in predicting the resilience. Relatively, this contribution is higher on optimism compared to social support.

Table 6. The result of linear regression analysis

\begin{tabular}{ccccc}
\hline Variables & B & Beta & T & Sig. \\
\hline (Constant) & 36.506 & & 11.853 & .000 \\
Social support & .285 & .204 & 4.199 & .000 \\
Optimism & 1.705 & .593 & 12.207 & .000 \\
$\mathrm{R}$ & .727 & & & \\
$\mathrm{R}^{2}$ & .528 & & & \\
Adjusted R & .525 & & & \\
F-Statistics & 160.986 & & & \\
\hline
\end{tabular}

Note. Significant at 0.01 level

\section{Discussion}

This study was conducted to determine the relationship between optimism, social support and resilience among international students of UPM, and to identify differences in demographic factors (gender and race) across the dependent variable (resilience) among students. Also, some interesting findings emerge as follows.

Firstly, the findings revealed a strong positive relationship between resilience and optimism and also high contribution of optimism in predicting resilience among students. It seems optimism and resilience appear to accompany each other in unfavorable situations. In fact, there is an interactive association among optimism and resilience. Previous literature well supported the findings, which argued that optimism reflects persons' positive attitude towards unfavorable condition and therefore assumed optimism as an important feature of resilience and there is a strong association among resilience and optimism among students (Carver et al., 2010; Dawson \& Pooley, 2013). A clear understanding of all results demonstrated students should try to enhance their optimism level by applying some changes in their lifestyles. Students can improve their knowledge about what can change their attitudes and which factors influence on their optimistic view. In fact, indirectly, they are going to increase their resilience and ability to overcome adversity and challenges.

Secondly, the findings of the current study showed a moderate relationship between resilience and social support. It means international students' resiliency is affected by friends, family, their relatives and special person in their life, such as their owner, neighbors, supervisor, lecturers, who support them financially and mentally. This finding may give an inducement to the students to find more friends and attend the community to find more groups and have contact with more people. This result is consistent with previous literature. According to Weidong et al. (2012) and Dawson and Pooley (2013) resilience was positively related with social support among students. Moreover, Wilks and Spivey (2010) indicated that social support systems applied significant, positive impact with each other and with resilience. 
Thirdly, the findings of study displayed clear differences in the level of resilience across different races (Middle-Easterner, African, and Asian). Also, the findings demonstrated that the mean of African is significantly different with Asian and Middle-Easterners. One direction to understand this finding is by thinking of civilization as an adaptive mechanism that facilitates groups of persons (different cultures) to develop policies to deal with adversities. College students seem to take their indications from their culture and combine these special strategies in their own resilience approaches to cope with challenging situations. Some research indicates a significant relationship between race and resilience as well. Based on research of Weaver (2009) it was revealed that cultural/ethnic identity and resilience have a positive significant relationship with each other. Moreover, in the study of Campbell-Sills, Cohan, and Stein (2006) some significant relationship between ethnicity and resiliency were found. Furthermore, Ziaian, de Anstiss, Antoniou, Baghurst, and Sawyer (2012) revealed that the high level of resilience among south Africans is mostly related to their spiritual beliefs. In fact, the results of studies illustrated, firstly, cultural differences which include values, religion and spiritual beliefs and environmental factors that have an important effect on shaping people's perspective about life's issues, and second, their influence in shaping person's ability to manage trouble and deal with adversities in their lifespan.

At the end, the result has not shown any differences in the resilience level across gender among international students. As mentioned in the literature review, the findings of this study is contrary to a few studies by Bonanno, Galea, Bucciarelli, and Vlahov (2007) and Weidong et al. (2012). However, the same results were achieved by Johnson (2011) on relationship between gender and resilience among college students. Then, it is supposed that different result could be obtained in different circumstances. Also, It seems there are some environmental factors in psychological stream which have a strong effect on the relationship at the level of resilience across gender, such as financial support, poverty, age group, and marital status. These factors could be considered in further studies. A numbers of studies also gained the similar results. The findings of their studies showed that there was no difference in the level of resilience across gender among students. For instance, in addition, a study of Splan, Brooks, Porr, and Broyles (2011) on 100 adults clearly indicated that gender differences were not significant and there was no effect of gender on level of resilience.

\section{Limitations and Future Research Direction}

Although this research makes contributions to many fields as they linked to the educational field, numbers of limitations have been declared. Also, a certain recommendation should be occupied in deliberation in the case with further research. The current research has margin to a number of factors. A number of protective factors and risk factors could be considered in further researches to open a new window in psychological field such as self-efficacy, coping strategies, hope, intimacy, poverty, family environment, and some more specific health index, like depression in mental health and psychological well-being and also an array of demographic factors which has an effect on resilience level. It might be able to discover a better model describing the link between resilience and other variables, especially among international students. Moreover, in order to have a deeper understanding of the resilience concept, further qualitative research should be conducted for assessing the interaction of different factors among students. Therefore, cross sectional studies cannot allocate cause-and-effect relationship between variables. In future studies, it is suggested that researcher use longitudinal study to reveal cause-and-effect relationship among variables. Further, in this study, the larger sample size was predicted to be more beneficial, although the study represents significant result.

\section{Practical Implications}

The results of the study could be helpful for educational psychologist, counselor, educators, educational researchers and curriculum developers to organize some programs to enhance coping and resilience level of students, which has a direct effect on students' performance and educational level. Overall, the conception of resilience has important implications in the field of educational psychology in five main functions: assessment, intervention, consultation, research, and training. In addition, the findings of the study might also provide social and psychological researchers and students with some features of personality and behaviors among individuals that need to be searched further. Information and concepts gained from this study could help students to manage and deal with their challenges.

Evidently, the findings of current research have significant policy implications for all universities to meet accountability demands for improving academic performance. As suggested in the recent studies, the variables used in this research can be learned and taught as a skill. Consequently, the office of international students or anyone in charge of international affairs in university or organization has a responsibility to establish policies for the purpose of promoting students' adaptability to cope with adversity and difficulties they faced and enhance their well-being. In this regards, they can hold workshops and seminars to make them more familiar with ways to 
increase their resilience and coping. Also, these facilities help them to find better solutions to confront with obstacles in new circumstances. The findings of this study is also hoped to be helpful to draw attention of the involved parties to organize some plan to increase the level of education and performance. New standards, curriculum, teaching methods, and other types of practices that focus directly on academics would be effective to help international students.

It is needed that educators, counselor and professionals note the evidence from present research and use it to enhance resilience development program among international students. Also the result can serve as resource materials for researchers, scientists, and university authorities who are interested to investigate issues in psychology such as resiliency, optimism, social support, and international students' experiments. Consequently, the results will assist as previous and supplementary evidence to reach a new outcome.

\section{References}

Beard, K. S., Hoy, W. K., \& Anita, W. H. (2010). Academic optimism of individual teachers: Confirming a new construct. Teaching and Teacher Education, 26(5), 1136-1144. http://dx.doi.org/10.1016/j.tate.2010.02.003

Berkman, L. F., Glass, T., Brissette, I., \& Seeman, T. E. (2000). From social integration to health: Durkheim in the new millennium. Social science \& medicine, 51(6), 843-857. http://dx.doi.org/10.1016/S0277-9536(00) 00065-4

Bernardon, S., Babb, K. A., Hakim-Larson, J., \& Gragg, M. (2011). Loneliness, attachment, and the perception and use of social support in university students. Canadian Journal of Behavioural Science/Revue canadienne des sciences du comportement, 43(1), 40. http://dx.doi.org/10.1037/a0021199

Bonanno, G. A, Galea, S., Bucciarelli, A., \& Vlahov, D. (2007). What predicts psychological resilience after disaster? The role of demographics, resources, and life stress. Journal of consulting and clinical psychology, 75(5), 671. http://dx.doi.org/10.1037/0022-006X.75.5.671

Bonanno, G. A. (2004). Loss, trauma, and human resilience: Have we underestimated the human capacity to thrive after extremely aversive events? American psychologist, 59(1), 20. http://dx.doi.org/10.1037/0003066X.59.1.20

Bronfenbrenner, U. (1986). Ecology of the family as a context for human development: Research perspectives. Developmental psychology, 22(6), 723. http://dx.doi.org/10.1037//0012-1649.22.6.723

Burcusa, S. L., \& Iacono, W. G. (2007). Risk for recurrence in depression. Clinical psychology review, 27(8), 959-985. doi: http://dx.doi.org/10.1016/j.cpr.2007.02.005

Campbell-Sills, L., Cohan, S. L., \& Stein, M. B. (2006). Relationship of resilience to personality, coping, and psychiatric symptoms in young adults. Behaviour research and therapy, 44(4), 585-599. http://dx.doi.org/10. 1016/j.brat.2005.05.001

Carver, C. S., \& Connor-Smith, J. (2010). Personality and coping. Annual review of psychology, 61, 679-704. http://dx.doi.org/10.1146/annurev.psych.093008.100352

Carver, C. S., \& Scheier, M. F. (2003). Three human strengthsPsychology of Human Strengths: Fundamental Questions and Future Directions for a Positive Psychology. A Psychology of Human Strengths. http://dx.doi.org/10.1037/10566-007

Carver, C. S., Scheier, M. F., \& Segerstrom, S. C. (2010). Optimism. Clinical psychology review, 30(7), 879-889. http://dx.doi.org/10.1016/j.cpr.2010.01.006

Chan, D. W. (2000). Dimensionality of hardiness and its role in the stress-distress relationship among Chinese adolescents in Hong Kong. Journal of Youth and Adolescence, 29(2), 147-161. http://dx.doi.org/10.1023/ A: 1005100531194

Chronister, J. A., Johnson, E. K., \& Berven, N. L. (2006). Measuring social support in rehabilitation. Disability \& Rehabilitation, 28(2), 75-84. http://dx.doi.org/10.1080/09638280500163695

Clauss-Ehlers, C. S., Yang, Y.-T. T., \& Chen, W.-C. J. (2006). Resilience from childhood stressors: The role of cultural resilience, ethnic identity, and gender identity. Journal of Infant, Child, and Adolescent Psychotherapy, 5(1), 124-138. http://dx.doi.org/10.2513/s15289168jicap0501_7

Compas, B. E., Wagner, B. M., Slavin, L. A., \& Vannatta, K. (1986). A prospective study of life events, social support, and psychological symptomatology during the transition from high school to college. American Journal of Community Psychology, 14(3), 241-257. http://dx.doi.org/10.1007/BF00911173 
Conchas, G. Q., \& Clark, P. A. (2002). Career academies and urban minority schooling: Forging optimism despite limited opportunity. Journal of Education for Students Placed at Risk, 7(3), 287-311. http://dx.doi.org/10.1207/S15327671ESPR0703_1

Creswell, J. W. (2009). Research Design: Qualitative, Quantitative, and Mixed Methods Approaches. SAGE Publications.

Dawson, M., \& Pooley, J. A. (2013). Resilience: The Role of Optimism, Perceived Parental Autonomy Support and Perceived Social Support in First Year University Students. Journal of Education and Training Studies, 1(2), 38-49. http://dx.doi.org/10.11114/jets.v1i2.137

Dent, R. J., \& Cameron, R. J. S. (2003). Developing resilience in children who are in public care: The educational psychology perspective. Educational Psychology in Practice, 19(1), 3-19. http://dx.doi.org/10. $1080 / 0266736032000061170$

DuMont, K. A., Widom, C. S., \& Czaja, S. J. (2007). Predictors of resilience in abused and neglected children grown-up: The role of individual and neighborhood characteristics. Child abuse \& neglect, 31(3), 255-274. http://dx.doi.org/10.1016/j.chiabu.2005.11.015

Dweck, C. S., \& Reppucci, N. Di. (1973). Learned helplessness and reinforcement responsibility in children. Journal of Personality and Social Psychology, 25(1), 109. http://dx.doi.org/10.1037/h0034248

Dziegielewski, S. F., Turnage, B., \& Roest-Marti, S. (2004). Addressing stress with social work students: A controlled evaluation. Journal of Social Work Education, 40(1), 105-119. http://dx.doi.org/10.1080/ 10437797.2004 .10778482

Earvolino-Ramirez, M. (2007). Resilience: A concept analysis. Paper presented at the Nursing Forum. http://dx.doi.org/10.1111/j.1744-6198.2007.00070.

Fergusson, D. M., Horwood, L. J., \& Swain-Campbell, N. R. (2003). Cannabis dependence and psychotic symptoms in young people. Psychological medicine, 33(1), 15-21. http://dx.doi.org/10.1017/S0033291702 006402

Fresco, D. M., Moore, M. T., Walt, L., \& Craighead, L. W. (2009). Self-administered optimism training: Mechanisms of change in a minimally supervised psychoeducational intervention. Journal of Cognitive Psychotherapy, 23(4), 350-367. http://dx.doi.org/10.1891/0889-8391.23.4.350

Friborg, O., Hjemdal, O., Rosenvinge, J. H., \& Martinussen, M. (2003). A new rating scale for adult resilience: What are the central protective resources behind healthy adjustment? International journal of methods in psychiatric research, 12(2), 65-76. http://dx.doi.org/10.1002/mpr.143

Gall, T. L., Evans, D. R., \& Bellerose, S. (2000). Transition to first-year university: Patterns of change in adjustment across life domains and time. Journal of Social and Clinical Psychology, 19(4), 544-567. http://dx.doi.org/10.1521/jscp.2000.19.4.544

Greenberger, E., Chen, C., Tally, S. R., \& Dong, Q. (2000). Family, peer, and individual correlates of depressive symptomatology among US and Chinese adolescents. Journal of Consulting and Clinical Psychology, 68(2), 209. http://dx.doi.org/10.1037/0022-006X.68.2.209

Hale, C. J., Hannum, J. W., \& Espelage, D. L. (2005). Social support and physical health: The importance of belonging. Journal of American College Health, 53(6), 276-284. http://dx.doi.org/10.3200/JACH.53.6. 276-284

Harris, P. (2004). Culturally competent disability support: Putting it into practice. Multicultural Disability Advocacy Association of NSW. http://dx.doi.org/10.1080/1177083X.2014.911752

Hjemdal, O., Vogel, P. A., Solem, S., Hagen, K., \& Stiles, T. C. (2011). The relationship between resilience and levels of anxiety, depression, and obsessive-compulsive symptoms in adolescents. Clinical Psychology \& Psychotherapy, 18(4), 314-321. http://dx.doi.org/10.1002/cpp.719

Johnson, E. L. (2011). Protective factors and levels of resilience among college students. The University of Alabama TUSCALOOSA.

Kawachi, I., \& Berkman, L. F. (2001). Social ties and mental health. Journal of Urban health, 78(3), 458-467. http://dx.doi.org/10.1093/jurban/78.3.458

Lee, M. N. (2011). Applying Risk and Resilience Framework in Examining Youth's Sustainability in Coping with Life's Challenges. International Journal of Trade, Economics \& Finance, 2(5). http://dx.doi.org/ 


\subsection{3/IJTEF.2011.V2.140}

Lekes, N., Gingras, I., Philippe, F. L., Koestner, R., \& Fang, J. (2010). Parental autonomy-support, intrinsic life goals, and well-being among adolescents in China and North America. Journal of youth and adolescence, 39(8), 858-869. http://dx.doi.org/10.1007/s10964-009-9451-7

Li, M.-H. (2008). Relationships among stress coping, secure attachment, and the trait of resilience among Taiwanese college students. College Student Journal, 42(2), 312-325. http://dx.doi.org/10.1037/a0016844

Lomax, R. G., \& Schumacker, R. E. (2012). A beginner's guide to structural equation modeling: Routledge Academic.

Masten, A. S. (2009). Ordinary Magic: Lessons from Research on Resilience in Human Development. Education Canada, 49(3), 28-32.

Meevissen, Y., Peters, M. L., \& Alberts, H. J. (2011). Become more optimistic by imagining a best possible self: Effects of a two week intervention. Journal of behavior therapy and experimental psychiatry, 42(3), 371-378. http://dx.doi.org/10.1016/j.jbtep.2011.02.012

Pritchard, M. E., Wilson, G. S., \& Yamnitz, B. (2007). What predicts adjustment among college students? A longitudinal panel study. Journal of American College Health, 56(1), 15-22. http://dx.doi.org/10.3200/ JACH.56.1.15-22

Ratelle, C. F., Larose, S., Guay, F., \& Senécal, C. (2005). Perceptions of parental involvement and support as predictors of college students' persistence in a science curriculum. Journal of Family Psychology, 19(2), 286. http://dx.doi.org/10.1037/0893-3200.19.2.286

Reynoso, N. A. (2008). Academic resiliency among Dominican English-language learners. Community College Journal of Research and Practice, 32(4-6), 391-434. http://dx.doi.org/10.1080/10668920701884364

Rutter, M. (2006). Implications of resilience concepts for scientific understanding. Annals of the New York Academy of Sciences, 1094(1), 1-12. http://dx.doi.org/10.1196/annals.1376.002

Scheier, M. F., Carver, C. S., \& Bridges, M. W. (1994). Distinguishing optimism from neuroticism (and trait anxiety, self-mastery, and self-esteem): a reevaluation of the Life Orientation Test. Journal of personality and social psychology, 67(6), 1063. http://dx.doi.org/10.1037//0022-3514.67.6.1063

Snyder, C. R., Feldman, D. B., Shorey, H. S., \& Rand, K. L. (2002). Hopeful choices: A school counselor's guide to hope theory. Journal of Personality and Social Psychology, 65, 1061-1070.

Soenens, B., Vansteenkiste, M., Lens, W., Luyckx, K., Goossens, L., Beyers, W., \& Ryan, R. M. (2007). Conceptualizing parental autonomy support: Adolescent perceptions of promotion of independence versus promotion of volitional functioning. Developmental psychology, 43(3), 633. http://dx.doi.org/10.1037/00121649.43.3.633

Splan, R. K., Brooks, R. M., Porr, S., \& Broyles, T. W. (2011). Resiliency and Achievement Goal Orientation among Agricultural Students. NACTA Journal, 55(4).

Tam, C. L., \& Lim, S. G. (2009). Perceived social support, coping capability and gender differences among young adults. Sunway Academic Journal, 6, 75-88. http://dx.doi.org/10.1080/10615800500472963

Taylor, S. E., \& Friedman, H. S. (2007). Social support. Foundations of health psychology, 145-171.

Troy, A. S., \& Mauss, I. B. (2011). Resilience in the face of stress: Emotion regulation as a protective factor. Resilience and mental health: Challenges across the lifespan, 30-44. http://dx.doi.org/10.1017/CBO 9780511994791.004

Tugade, M. M., \& Fredrickson, B. L. (2007). Regulation of positive emotions: Emotion regulation strategies that promote resilience. Journal of Happiness Studies, 8(3), 311-333. http://dx.doi.org/10.1007/s10902-0069015-4

Tusaie, K. R., \& Patterson, K. (2006). Relationships among trait, situational, and comparative optimism: clarifying concepts for a theoretically consistent and evidence-based intervention to maximize resilience. Archives of psychiatric nursing, 20(3), 144-150. http://dx.doi.org/10.1016/j.apnu.2005.10.004

Tusaie, K., \& Dyer, J. (2004). Resilience: A historical review of the construct. Holistic nursing practice, 18(1), 3-10. doi: http://dx.doi.org/10.1097/00004650-200401000-00002

Tusaie, K., Puskar, K., \& Sereika, S. M. (2007). A predictive and moderating model of psychosocial resilience in adolescents. Journal of Nursing Scholarship, 39(1), 54-60. http://dx.doi.org/10.1111/j.1547-5069.2007. 
00143.X

Tusaie-Mumford, K. (2001). Psychosocial resilience in rural adolescents: Optimism, perceived social support and gender differences. University of Pittsburgh.

Ungar, M. (2008). Resilience across cultures. British journal of social work, 38(2), 218-235. http://dx.doi.org/10. 1093/bjsw/bcl343

Walker, B., Gunderson, L., Kinzig, A., Folke, C., Carpenter, S., \& Schultz, L. (2006). A handful of heuristics and some propositions for understanding resilience in social-ecological systems. Ecology and society, 11(1), 13.

Weidong, J., Guoquan, Z., Yaosheng, P., Shumin, Z., Daoliang, Y., Guangyao, L., \& Yongyong, S. (2012). P-1407-Relationship between resilience and social support, coping style of students in middle school. European Psychiatry, 27, 1. http://dx.doi.org/10.1016/S0924-9338(12)75574-8

Wilks, S. E., \& Spivey, C. A. (2010). Resilience in Undergraduate Social Work Students: Social Support and Adjustment to Academic Stress 1. Social Work Education, 29(3), 276-288. http://dx.doi.org/10.1080/ 02615470902912243

Wilson, M. N., Hurtt, C. L., Shaw, D. S., Dishion, T. J., \& Gardner, F. (2009). Analysis and influence of demographic and risk factors on difficult child behaviors. Prevention Science, 10(4), 353-365. http://dx.doi.org/10.1007/s11121-009-0137-x

Wright, M. O’D., \& Masten, A. S. (2005). Resilience processes in development. Handbook of resilience in children (pp. 17-37). Springer.

Yi-Frazier, J. P., Smith, R. E., Vitaliano, P. P., Yi, J. C., Mai, S., Hillman, M., \& Weinger, K. (2010). A personfocused analysis of resilience resources and coping in patients with diabetes. Stress and health, 26(1), 51-60. http://dx.doi.org/10.1002/smi. 1258

Zautra, A. J., Hall, J. S., \& Murray, K. E. (2010). A New Definition of Health for People and Communities. Handbook of adult resilience, 1 .

Ziaian, T., de Anstiss, H., Antoniou, G., Baghurst, P., \& Sawyer, M. (2012). Resilience and its association with depression, emotional and behavioural problems, and mental health service utilisation among refugee adolescents living in South Australia. International Journal of Population Research, 2012. http://dx.doi.org/10.1155/2012/485956

Zimet, G. D., Dahlem, N. W., Zimet, S. G., \& Farley, G. K. (1988). The multidimensional scale of perceived social support. Journal of personality assessment, 52(1), 30-41. http://dx.doi.org/10.1207/s15327752 jpa5201_2

\section{Copyrights}

Copyright for this article is retained by the author(s), with first publication rights granted to the journal.

This is an open-access article distributed under the terms and conditions of the Creative Commons Attribution license (http://creativecommons.org/licenses/by/3.0/). 